\title{
Effect of the Number and Orientation of Fractures on the P-Wave Velocity Diminution: Application on the Building Stones of the Rabat Area (Morocco)
}

\author{
Hamid El Azhari ${ }^{1}$, Iz-Eddine El Amrani El Hassani ${ }^{2}$ \\ ${ }^{1}$ Département de Géologie, Faculté des Sciences, Université Mohammed V-Agdal (Maroc), Rabat, Morocco \\ ${ }^{2}$ Département des Sciences de la Terre, Institut Scientifique, Université Mohammed V-Agdal (Maroc), \\ Equipe de Géomatériaux et Géo-Environnement (GeoM\&E), Rabat, Morocco \\ Email: elazharihamid1@yahoo.fr
}

Received April 23, 2013; revised May 23, 2013; accepted June 1, 2013

Copyright (C) 2013 Hamid El Azhari, Iz-Eddine El Amrani El Hassani. This is an open access article distributed under the Creative Commons Attribution License, which permits unrestricted use, distribution, and reproduction in any medium, provided the original work is properly cited.

\begin{abstract}
This study is focused on two types of Moroccan rocks, among the most widely used as building stones: the calcarenite of Salé (CS) and the marble of oued Akrech (MA). The two rocks, lithologically different, show a clear contrast of their P-wave velocities (Vp): $3.90 \mathrm{vs} 5.10 \mathrm{~km} / \mathrm{s}$ at dry state and $4.29 \mathrm{vs} 5.64 \mathrm{~km} / \mathrm{s}$ at saturation. The "Artificial fractures" created in the two rock types reveal that their Vp undergo diminutions which the rates vary depending of the number and the plane orientation of the fractures. In the CS, Vp shows an increasing of cumulative diminution (Dc) according to the number of fractures, but with a variable rate of unitary diminution $(\mathrm{Du})$ from one fracture to the other. This defines a linear regression with a low coefficient of determination $\left(\mathrm{Dc}=10.18 \mathrm{NbFr}+10.96 ; r^{2}=0.87\right)$. The mode of the $\mathrm{Vp}$ evolution would be related to the roughness of fractures surface, which itself depends upon the petrographic nature of the calcarenite (friable structure, high porosity and heterogenous composition). The MA manifested an increasing Dc with a fairly constant rate of $\mathrm{Du}$ from a fracture to another, giving a regression line with a high coefficient of determination $\left(\mathrm{Dc}=12.17 \mathrm{NbFr}-10.69 ; r^{2}=0.99\right)$. This steady diminution of $\mathrm{Vp}$ would be related to the granoblastic texture and the monomineral composition of the marble, which engender smoother fracture surfaces. The rates of $\mathrm{Vp}$ diminution also depend on the orientation plane of the fractures relative to the direction of wave propagation. The fractures parallel $\left(\theta=0^{\circ}\right)$ amplify slightly the Vp, playing a significant role of "waveguide". The fractures oriented at $45^{\circ}$ lead to a diminution lower than those of fractures oriented at $25^{\circ}$ and $90^{\circ}$. The same trend of diminution, but at variable rates, appears on the samples of the two types of stones at dry and saturated state. This can be explained by the compressive nature of P-waves, which obey the physic laws of the transmission of the constraints in the solid mediums.
\end{abstract}

Keywords: Fracture; Diminution; P-Wave Velocity; Calcarenite; Marble; Morocco

\section{Introduction}

Tectonics deformation and stress are the main factors of rocks fracturing. Extraction of ornamental stones, especially by using explosives, is also responsible for discrete fractures (microcracks). The fracture network developed in the rocks affects their inner cohesion and reduces their own mechanical strength. Indeed, these fractures facilitate the penetration of fluids inside the rock thereby accelerating its chemical weathering and consequently affect its physical properties [1].

Detection of fractures in rocks is of the utmost importance. In engineering and mining works, it will assess the strength of rock formations in order to know the most suitable technical roof-supporting to use. In the construction field, it allows to select both in the quarries than marble factories the blocks of good quality (without microfractures). Concerning the implemented stones, assess of their fracturing level leads to predict their potential risk.

Measurement of P-wave velocity $(\mathrm{Vp})$ has been proven as an effective approach to appreciate the petro-physical properties of rocks [2-11]. These studies have shown actually that each type of stone can be characterized by a well-defined $\mathrm{Vp}$. In fact, the values of $\mathrm{Vp}$ are closely related to intrinsic parameters of the stones, including petrography, mineralogy, grain size, texture, porosity, density, hardness, compressive strength, fluid saturation. 
Some investigations were focused specially on the cracks in the rocks attempting to understand the relation between the characteristic of P-wave velocities and the properties of the fractured medium. This plays an crucial role in developing a certain number of physical models, showing that the waveform, the amplitude and velocity of transmitted waves are greatly influenced, first by the manner and nature that the fractures are represented, second by the size, number, thickness, aperture, infilling... of the fractures [1,12-15].

Experimental studies of Kahraman [6,16] carried out on three types of stone (granite, marble and travertine) containing artificial joints (fractures) showed that $\mathrm{P}$-wave velocity $(\mathrm{Vp})$ decrease with an increase of the number of joints $(\mathrm{JN})$. Furthermore, values of $\mathrm{Vp}$ rely on the hardness of the rocks, assessed by the rebound number of the Schmidt hammer (RN), and roughness of fracture surfaces, which are artificially created by sawing. Investigations on the relationships between $\mathrm{Vp}$ and joints density (J) permitted Altindag [17] to confirm the results of Kahraman [16] concerning the decrease of $\mathrm{Vp}$ with the increase of the number of joints.

They, furthermore, highlighted a good polynomial correlation between the number of joints and the reduction rate in $\mathrm{Vp}(\%)$ indicating that $\mathrm{P}$-wave velocities are rapidly attenuated with the augmentation of the joints density.

The purpose of this paper is to deepen knowledge of the effects of both the number and the orientation of the fractures on the diminution rates of $\mathrm{Vp}$. Results of this study aim to bring to researchers and engineers some extra interpretation elements on the fluctuation of $\mathrm{Vp}$ values occurring into the same types of rocks; fluctuations which are frequently related to the problem of rock fracturing, especially when the fractures are discreet and not highlighted by iron oxides or other fillings. This would contribute to improve the efficiency of ultrasonic wave method for monitoring and quality control of building stones.

\section{Materials and Method}

\subsection{Stones under Study}

This study has been conducted by using two types of Moroccan rock, which are geologically and lithologically different: the calcarenite of Salé and the marble of oued Akrech. These two rocks outcrop extending over a $20 \mathrm{~km}$ radius around the city of Rabat, the capital of Morocco (Figure 1).

The calcarenite of Salé (CS) is a detritic sedimentary rock of the Plio-Quaternary. It composes a part of the post-Paleozoic cover of the Rabat area and forms a system of dunes that stretch over several kilometers along the Atlantic coast [18]. The rock is gray-beige, medium- grained and shows a rough surface. At the microscopic level, it presents a heterogeneous granular texture composed of quartz grains and shell fragments of bivalves bound each other by a carbonate cement of micritic type (Figures 2(a) and (b)).

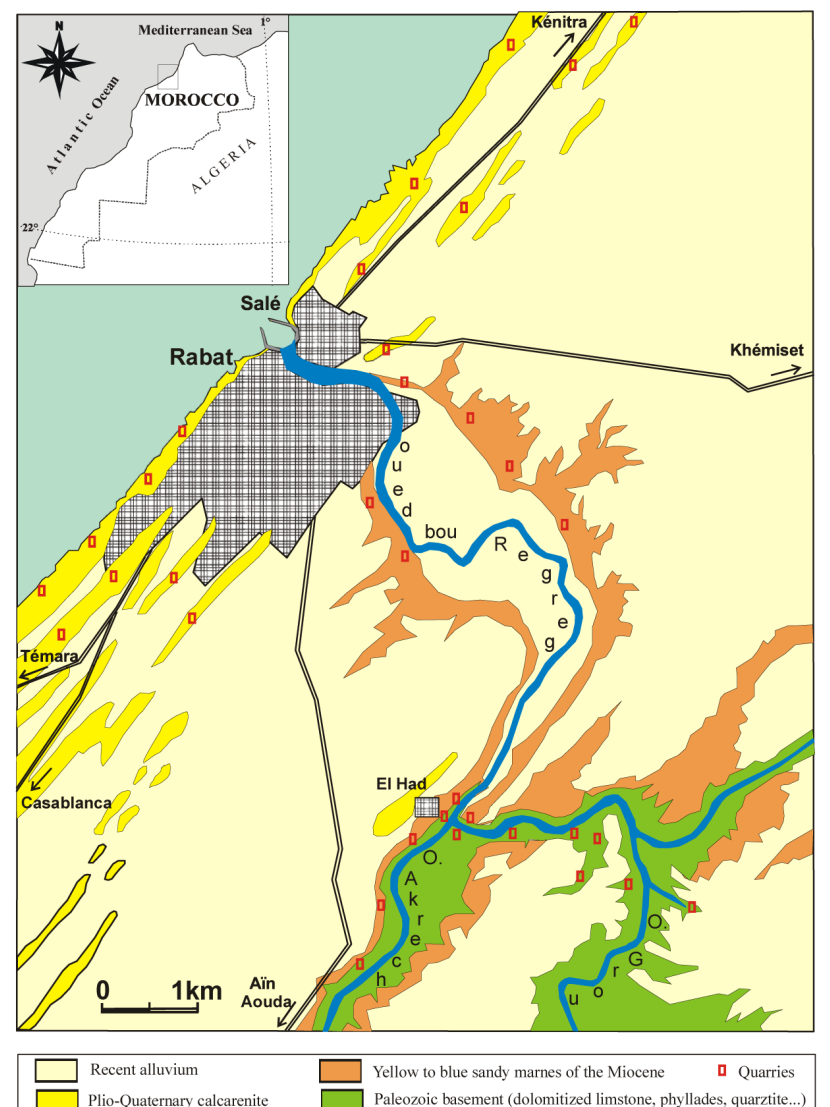

Figure 1. Outcrop map of calcarenite and marble around the region of Rabat-Salé (from the geotechnical map of Rabat, Morocco: 1/50,000—1970, simplified).
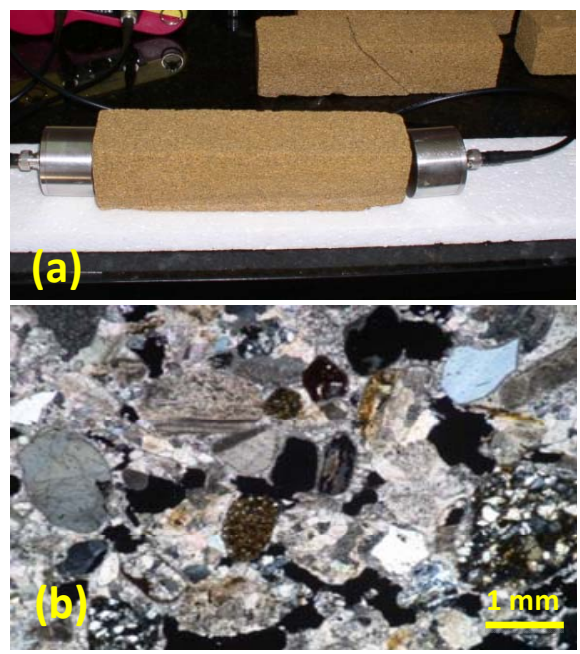

Figure 2. Calcarenite of Salé: (a) Macroscopic appearance; (b) Microscopic observation under polarized light. 
The marble of oued Akrech (MA) is a carbonate metamorphic rock of lower Devonian. It belongs to the Paleozoic basement of the Rabat area [18]. The rock is pinkish-gray, with massive structure and a granular aspect. The texture is granoblastic and composed mainly of imbricate crystals of carbonate (calcite and dolomite) with a few shell fragments of echinoderms and polypiers (Figures 3(a) and (b)).

The two rocks were highly demanded as building stones of the Rabat and Salé regions since prehistoric times: they were found both in the Roman ruins of Chellah and monument of Hassan Tour (Almohad period: XII-XIII century) of which the tower is built in calcarenite and the pillars in marble (Figures 4(a) and (b)). These same materials remain until now the building stones of choice for traditional and modern buildings of Rabat and its regions [10,19-21].

\subsection{Measuring Instrument}

Measurements of P-wave velocity ( $\mathrm{Vp}$ ) were carried out with a portable instrument (type TICO) manufactured by Controlab according to the French standard (NF P 94-411). The device includes an electric pulse generator (250 volts, 0.1 to $6500 \mu \mathrm{s}, 1 \mathrm{pulse} / \mathrm{s})$ and two piezoelectric transducers (a transmitter and a receiver) providing ultrasonic waves $(45 \mathrm{kHz})$. Measurement principle consist to applying the transducers on the two parallel faces of a rock specimen having a determinate length (L) and trigger a series of ultrasound pulses. The device calculates the time interval $(\mathrm{t})$ between the start and reception of the pulses. The $\mathrm{Vp}$ in the specimen is calculated from the simple relation $(\mathrm{Vp}=\mathrm{L} / \mathrm{t})$ and it is expressed in $\mathrm{km} / \mathrm{s}$.

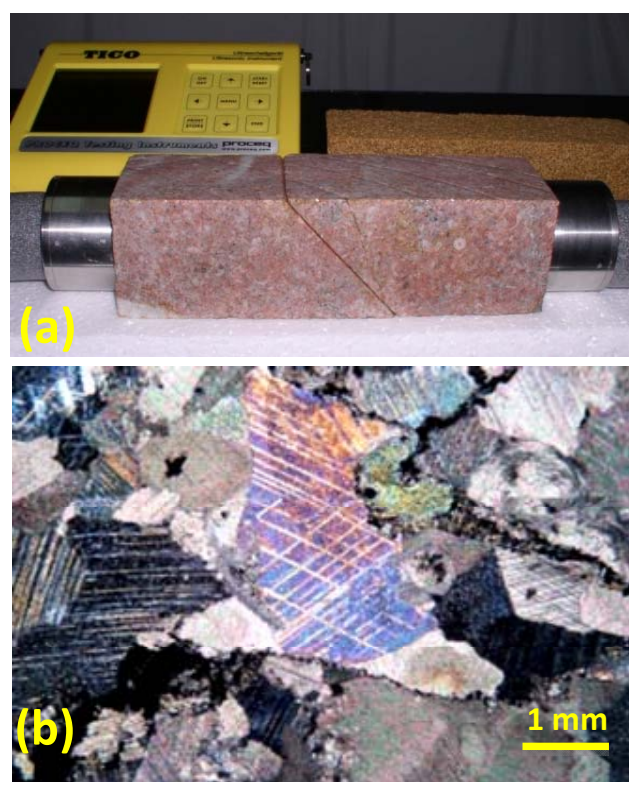

Figure 3. Marble of oued Akrech: (a) Macroscopic appearance; (b) Microscopic observation under polarized light.
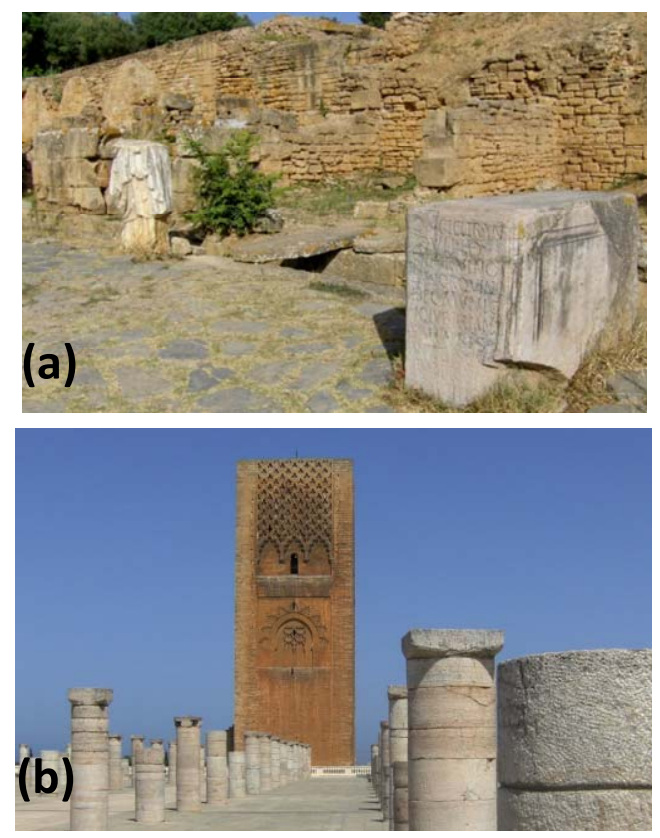

Figure 4. Calcarenite of Salé and marble of oued Akrech: (a) The Roman site of Chellah; (b) The Almohade Tour of Hassan.

\subsection{Experimental Model}

Rock specimens having a dimension of $5 \times 5 \times 20 \mathrm{~cm}^{3}$ were cut, in laboratory with a diamonded saw, from homogenous blocks of calcarenite and marble (CS and MA). A specimen of each rock-type was kept intact while the others were sawed in order to generate "artificial fractures" in well-defined number and according to precise orientation plans, as shown in Figure 5.

Measurements of $\mathrm{Vp}$ were performed according to the ASTM recommendation, regarding measurements of ultrasonic wave velocities in natural stones (D 2845-00) [22]. In this regard, some precautions have been taken to ensure a better quality of measures:

Rectification of the end surfaces of specimens (artificial fractures surfaces) to eliminate irregularities caused by the sawing.

Using of a clamp for a good coupling of the surface fractures.

Application of glycerin (Ref.: 325-40-040, Koppelmittel zu TICO) between transducers and specimen to minimize wave loss at the interface.

Finally, these measurements of $\mathrm{Vp}$ were performed both on dry samples $\left(24 \mathrm{~h}\right.$ at $\left.110^{\circ} \mathrm{C}\right)$ and saturated ones (emersion in distilled water for $48 \mathrm{~h}$ ).

\section{Presentation of Results}

\subsection{Petrophysical Data}

Five physical and mechanical tests were applied to the two stones (calcarenite of Salé and marble of oued Ak- 


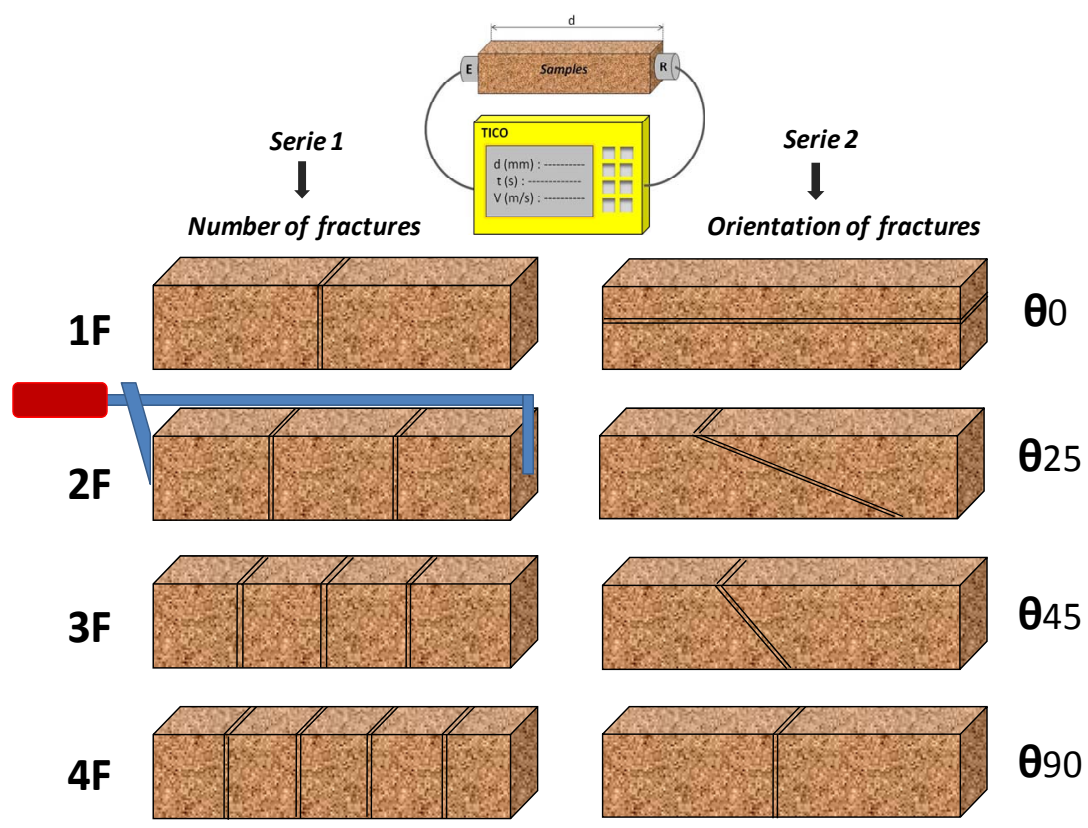

Figure 5. Procedure of Vp measurement on samples showing a different number and a variable orientation of fractures.

rech) under study: Mohs Hardness (MH); Effective Density (ED); Water Absorption (WA) Open Porosity (OP); Uniaxial Compressive Strength (UCS). The tests were executed following the recommendations of ASTM norm (References: C97-02 for ED and WA; D 4404-98 for OP; D 2845-00 for UCS).

Table 1 summarizes petrographical characters and results of physico-mechanical tests of the two stones (CS and MA):

Good correlations appear between different petrophysical parameters; the calcarenite of Salé shows a low density due to its high porosity. Its low compressive strength expresses the crumbly nature of micritic cement and reflects the low cohesion between its constituent minerals.

On the other hand, the marble of oued Akrech has a higher density because of its relatively low porosity. Its granoblastic texture, with well-imbricate crystals, gives the rock a good internal cohesion and consequently a high compressive strength.

\subsection{Effect of the Length}

The attenuation $(\alpha)$ of P-wave velocities is a physical parameter, which depends on intrinsic characteristics of the solid medium. It expresses the loss of velocity as a function of the distance traveled by the waves [23]. So, preliminary measurements of $\mathrm{Vp}$ were conducted on intact specimens (without fractures) having the same section $\left(5 \times 5 \mathrm{~cm}^{2}\right)$ but variable lengths $\left(5\right.$ to $\left.60 \mathrm{~cm}^{2}\right)$ in orer to detect the effect of the specimen length on the attenuation of Vp. The results are presented in Table 2.

The data in Table 2 show that $\mathrm{Vp}$ values of specimens shorter than $15 \mathrm{~cm}$ appear aberrant as illustrates in Fig- ure 6. However, specimens whose lengths range between 15 and $60 \mathrm{~cm}$ show a good stability of $\mathrm{Vp}$ values with insignificant attenuation $(\alpha<5 \%)$. The rate of attenuations appears to be the same for the two types of stones under study, both in dry and saturated state.

These preliminary measurements indicate that the $\mathrm{Vp}$ values can be only valid on samples having at least a length equal or greater than $15 \mathrm{~cm}$. This minimum length is imposed by the frequency of the used transducers ( 45 $\mathrm{kHz}$ ).

Thus, length variations of specimen, ranging between 15 and $60 \mathrm{~cm}$ (limits of specimen lengths used in this work), have no significant influence on the measured $\mathrm{Vp}$ values.

\subsection{Effect of the Fracture Number}

$\mathrm{Vp}$ measurements are performed on rock specimens having different number of fractures (from 1 to 8 ), as explained previously (Figure 5). In this work, we express the loss of the velocity caused by the fractures under the term of diminution, which is physically distinct from the attenuation $(\alpha)$. So, two types of diminutionare calculated:

Unitary diminution $(\mathrm{Du})$ corresponding to a loss of $\mathrm{Vp}$ caused by each fracture considered apart:

$$
\mathrm{Du}=100\left(\mathrm{Vp}_{(\mathrm{x}-1) \mathrm{F}}-\mathrm{Vp}_{\mathrm{xF}}\right) / \mathrm{Vp}_{(\mathrm{x}-1) \mathrm{F}}
$$

$\mathrm{x}$ : number of fractures (from 1 to 8 ), $0 \mathrm{~F}$ : corresponds to the intact rock specimen (without fractures).

Cumulative diminution $(\mathrm{Dc})$ corresponding to the cumulated loss of $\mathrm{Vp}$ related to the combined effect of 2, 3 or 8 fractures. 
Table 1. Petro-mineralogical composition and physico-mechanical properties of the two varieties of building stones (calcarenite of Salé and marble of oued Akrech) under study (UCS: Uniaxial Compressive Strength).

\begin{tabular}{|c|c|c|}
\hline & Calcarenite of Salé (CS) & Marble of oued Akrech (MA) \\
\hline Nature \&origin & Sedimentary, detritic & Metamorphic, carbonate \\
\hline Composition & Quartz + shell fragments (Lamellibranch) + micrite & $\begin{array}{c}\text { Calcite }+ \text { dolomite }+ \text { shell fragments } \\
\text { (Echinoderm, Polyp) }\end{array}$ \\
\hline Texture & $\begin{array}{l}\text { Angular to rounded grains }(1-4 \mathrm{~mm}) \\
\text { bound by micritic cement. }\end{array}$ & $\begin{array}{l}\text { Granoblastic texture; crystal }(3-6 \mathrm{~mm}) \\
\text { contiguous with meshed contacts }\end{array}$ \\
\hline Hardness (Mohs) & 4 à 7 & $3-4$ \\
\hline Density & $1.43-1.72$ & $2.66-2.73$ \\
\hline Porosity $(\%)$ & $25.3-46.2$ & $0.28-0.45$ \\
\hline Water absorption (\%) & $17.5-23.6$ & $0.17-0.23$ \\
\hline UCS (MPa) dry state & $45-71$ & $100-108$ \\
\hline UCS (MPa) saturated & $42-62$ & $89-95$ \\
\hline
\end{tabular}

Table 2. The attenuation $(\alpha)$ of Vpaccording tothe length in the calcarenite of Salé and marble of ouedAkrech.

\begin{tabular}{|c|c|c|c|c|c|c|c|c|}
\hline \multirow[b]{2}{*}{ L Sample } & \multicolumn{4}{|c|}{ Calcarenite of Salé (CS) } & \multicolumn{4}{|c|}{ Marble of oued Akrech (MA) } \\
\hline & Vpdry & $\alpha(\%)$ & Vpsat & $\alpha(\%)$ & Vpdry & $\alpha(\%)$ & Vpsat & $\alpha(\%)$ \\
\hline 5 & 3.70 & - & 3.70 & - & 3.70 & - & 3.70 & - \\
\hline 10 & 2.83 & - & 3.11 & - & 4.55 & - & 5.10 & - \\
\hline 15 & 3.75 & 3.80 & 4.24 & 1.12 & 4.83 & 5.29 & 5.42 & 3.83 \\
\hline 20 & 3.83 & 1.74 & 4.33 & 0.98 & 5.12 & 0.39 & 5.70 & 1.14 \\
\hline 30 & 3.92 & 0.56 & 4.24 & 1.12 & 5.12 & 0.39 & 5.61 & 0.64 \\
\hline 40 & 4.00 & 2.62 & 4.30 & 0.28 & 5.20 & 1.69 & 5.70 & 1.14 \\
\hline 60 & 3.99 & 2.36 & 4.33 & 0.98 & 5.23 & 2.55 & 5.75 & 2.02 \\
\hline $\mathrm{Vp}^{*}$ & 3.90 & & 4.29 & & 5.10 & & 5.64 & \\
\hline
\end{tabular}

$\left(\mathrm{Vp}^{*}:\right.$ average values $)$

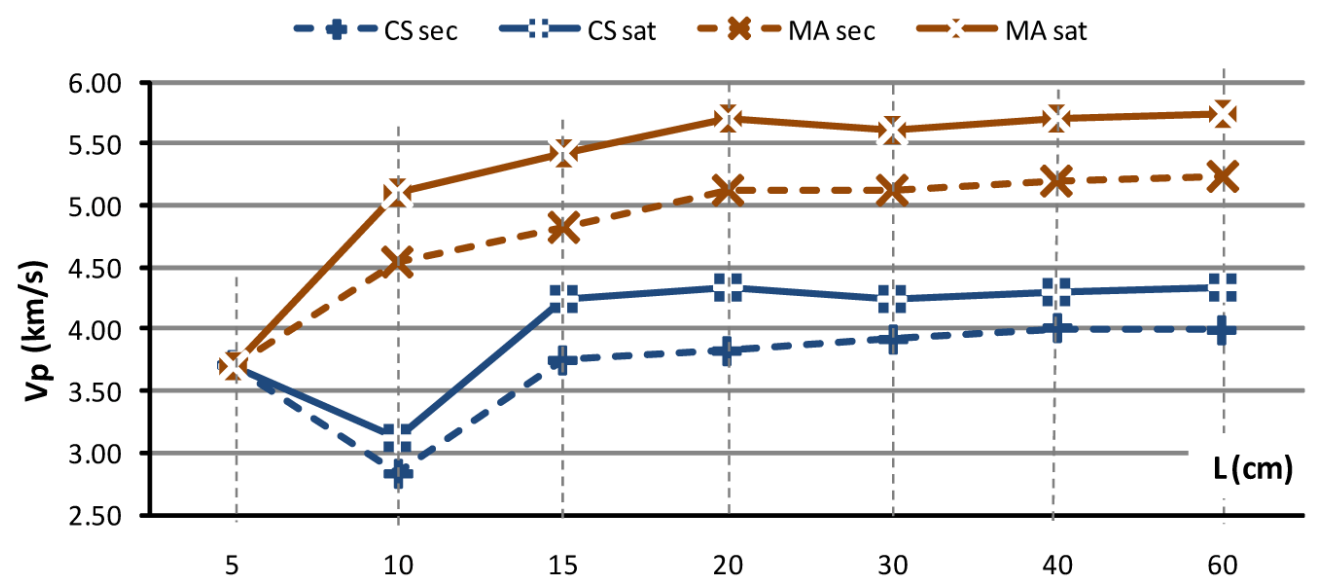

Figure 6. Variation of $\mathrm{Vp}$ vs Length in the calcarenite and marble rocks under dry and saturated state (CS dry/sat: Calcarenite of Salé dry/saturated; MA dry/sat: Marble of oued Akrech dry/saturated).

$$
\mathrm{Dc}=100\left(\mathrm{Vp}_{0 \mathrm{~F}}-\mathrm{Vp}_{\mathrm{xF}}\right) / \mathrm{Vp}_{0 \mathrm{~F}}
$$

Measurements of $\mathrm{Vp}$, Du and Dc concerning the rocks under study appear in the Table 3. 
Concerning the calcarenite of Salé (CS), the values of $\mathrm{Vp}$ decrease gradually with an increasing number of fractures (Figure 7) with a weak and constant deviation (about $0.4 \mathrm{~km} / \mathrm{s}$ ) between the dry and saturated samples. This reflects a progressive diminution (Dc) which is however very irregular. This irregularity appears clearly when we compare the unitary diminution rates $(\mathrm{Du})$ of the fractures. Actually, the rate of diminution varies from a fracture to another within the limits of $8 \%$ to $42 \%$. When it is beyond eight fractures, the diminution of $\mathrm{Vp}$ is total $(100 \%)$.

Whereas the marble of oued Akrech, reveals a typical profile of regression of $\mathrm{Vp}$ according to the fractures number, with a larger deviation $(1-1.5 \mathrm{~km} / \mathrm{s})$ between dry and saturated specimens (Figure 7).

The Vp diminution rates increase moderately and rela- tively more regular; the diminution rates are quite low for the first fractures, then they become more important after six. Unlike the calcarenite, a proportion of P-waves continue to be transmitted beyond eight fractures.

\subsection{Effect of the Orientation of Fractures}

The measuring protocol of $\mathrm{Vp}$ diminution according to the orientation of fractures (Do) is shown in Figure 5. The values of this diminution (Do) are obtained as following:

$$
\mathrm{Do}=100\left(\mathrm{Vp}_{\mathrm{OF}}-\mathrm{Vp}_{\theta}\right) / \mathrm{Vp}_{\mathrm{OF}}
$$

where the angle $\theta=0^{\circ} ; 25^{\circ} ; 45^{\circ} ; 90^{\circ}$.

The results of Vp measurement on samples with a single fracture at different orientations $\left(\theta=0^{\circ}, 25^{\circ}, 45^{\circ}\right.$ and $90^{\circ}$ ) are presented in Table 4.

Table 3. Variations of $\mathrm{Vp}$, Dc and Du according to the number of fractures ( $\mathrm{NbFr}=0$ to 8$)$ ) in both calcarenite of Salé and marble of oued Akrech, at dry and saturated state.

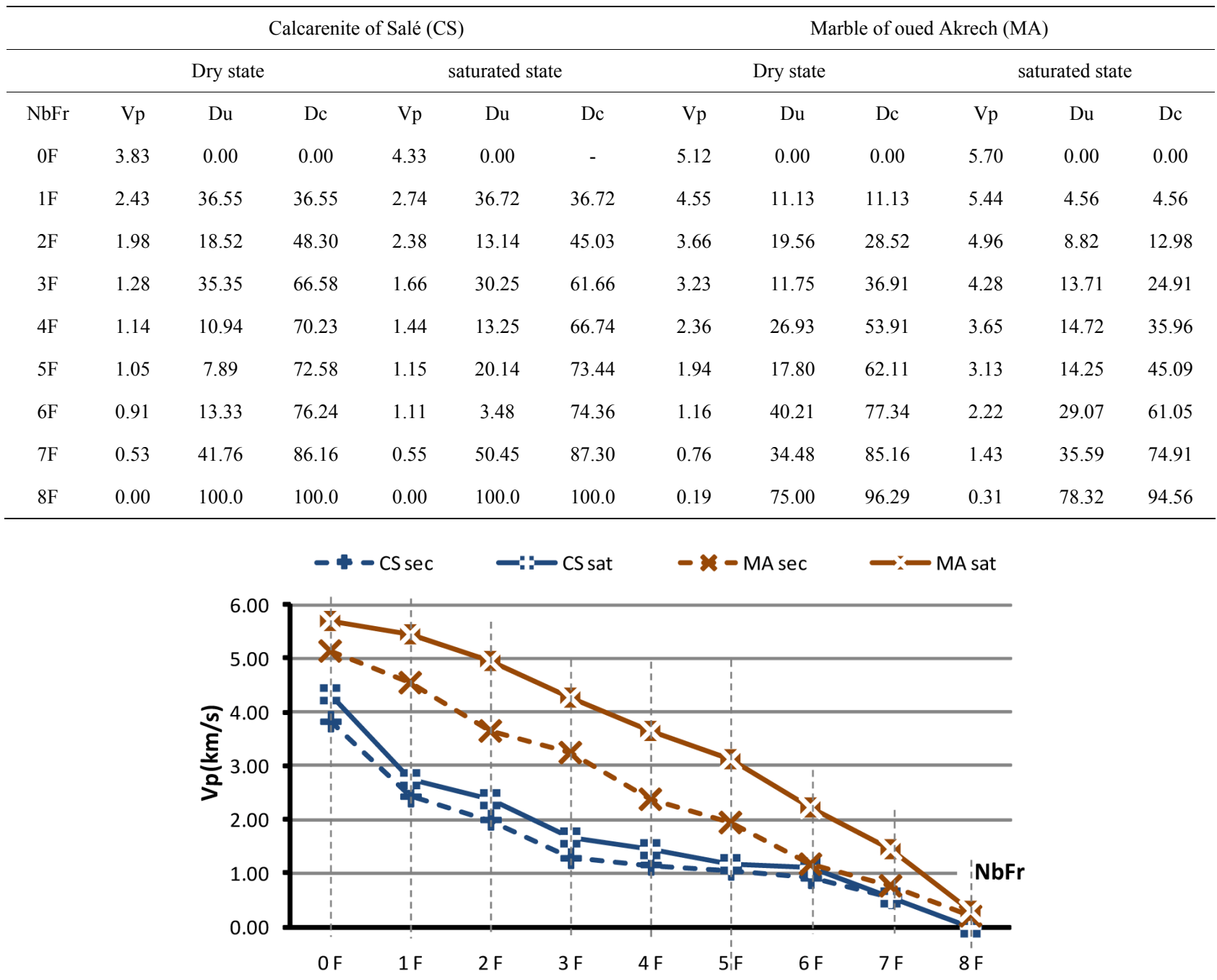

Figure 7. Evolution of $\mathrm{Vp}$ according to the number of fractures $(\mathrm{NFr}=\mathbf{0}$ to 8$)$ in the calcarenite of Salé and marble of oued Akrech, at dry and saturated conditions (the same legend as Figure 6). 
The diminution rate of $\mathrm{Vp}$ reveals a close relationship with the plane orientation of fractures. Leaving aside the differences between dry and saturated state, the diminution appears to evolve in the same direction for both types of stones: calcarenite of Salé and marble of oued Akrech (Figure 8).

These relationships between the $\mathrm{Vp}$ and the orientation of fracture planes lead us to highlight the following three main points:

1) Fractures oriented parallel to the direction of ultrasonic waves propagation $(\theta 0)$ doesn't cause loss of speed. On the contrary, they appear to cause a slight increase in $\mathrm{Vp}$, which can reach $3 \mathrm{~km} / \mathrm{s}$ (in the case of the dry marble).

2) $\mathrm{Vp}$ diminution is maximum for the fractures oriented at $25^{\circ}$ and $90^{\circ}$, with rates significantly stronger in the calcarenite of Salé (up to $40 \%$ at dry and almost $45 \%$ at saturated state) than in the marble of oued Akrech (16 $\%$ at dry; $10 \%$ at saturated state).

3) Fractures oriented at $45^{\circ}$ cause a more lower diminutions than those related to fractures oriented at $25^{\circ}$ and $90^{\circ}$. This is more noticed in the calcarenite of Salé $(28 \%$ at dry; $20 \%$ at saturated) than in the marble of the oued Akrech (5\% at dry; $2 \%$ at saturated).

\section{Discussion}

The average value of P-wave velocity $(\mathrm{Vp})$ of the calcarenite of Salé (CS) in dry state $(3.90 \mathrm{~km} / \mathrm{s})$ is much lower than the $\mathrm{Vp}$ of the marble of oued Akrech(MA) at the same state $(5.10 \mathrm{~km} / \mathrm{s})$. These values of P-wave velocity are consistent with those published on the equivalent stones from different regions of the world [16,17,2326]. Remembering that the P-wave velocity in the natural stone is directly related to their elastic constants, notably Young's modulus $(E)$ and density $(\rho)$ and expressed as:

$\mathrm{Vp}=\sqrt{\frac{E}{\rho}}$. The two physical parameters $(E$ and $\rho)$ depend mainly on the mineralogical composition, the texture and the porosity of the rock so each variety of stone has a specific value of $\mathrm{Vp}$. The geological and lithological origin of the calcarenite and marble are very different (Figures 2 and 3, Table 1) and explain the contrast between their Vp (Table 2). Until now, several studies have been

Table 4. Variations of Vp and Do according to the plan of fractures orientation.

\begin{tabular}{|c|c|c|c|c|c|c|c|c|}
\hline \multirow[b]{3}{*}{$\theta$} & \multicolumn{4}{|c|}{ Calcarenite of Salé (CS) } & \multicolumn{4}{|c|}{ Marble of oued Akrech (MA) } \\
\hline & \multicolumn{2}{|c|}{ dry } & \multicolumn{2}{|c|}{ saturated } & \multicolumn{2}{|c|}{ dry } & \multicolumn{2}{|c|}{ saturated } \\
\hline & $\mathrm{Vp}$ & Do & $\mathrm{Vp}$ & Do & $\mathrm{Vp}$ & Do & $\mathrm{Vp}$ & Do \\
\hline $0 \mathrm{~F}$ & 3.83 & 0.00 & 4.33 & 0.00 & 5.12 & 0.00 & 5.70 & 0.00 \\
\hline$\theta 0$ & 3.89 & -1.57 & 4.55 & -5.08 & 5.42 & -5.86 & 5.83 & -2.28 \\
\hline$\theta 25$ & 2.29 & 40.21 & 2.39 & 44.80 & 4.30 & 16.02 & 5.16 & 9.47 \\
\hline$\theta 45$ & 2.75 & 28.20 & 3.45 & 20.32 & 4.85 & 5.27 & 5.61 & 1.58 \\
\hline$\theta 90$ & 2.43 & 36.55 & 2.74 & 36.72 & 4.55 & 11.99 & 5.44 & 8.07 \\
\hline
\end{tabular}

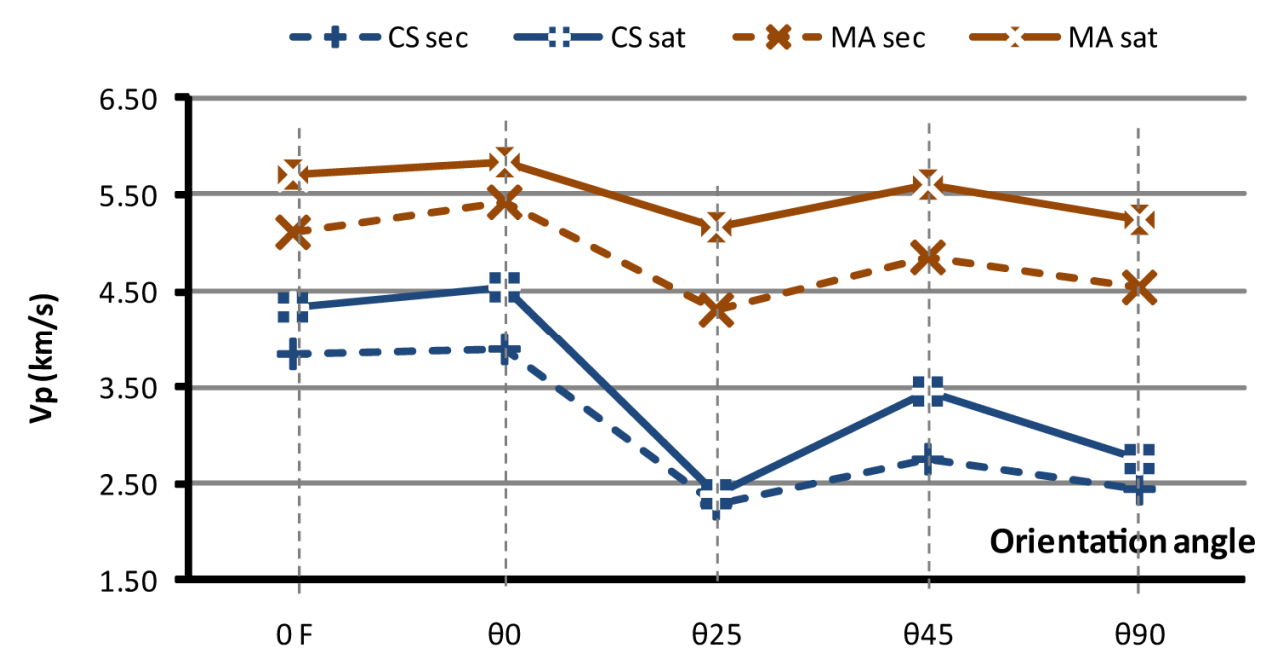

Figure 8. Evolution of $\mathrm{Vp}$ according to the plan orientation of the fractures in the calcarenite of Sale and the marble of oued Akrech, at dry and saturated state (the same legend as Figure 6). 
devoted to the relationships between the $\mathrm{Vp}$ and petrophysical characteristics of stones [8-11].

In the case of water saturation state, $\mathrm{Vp}$ increase in both types of stones as showed in the anterior researches [28]. Indeed, the Vp of our stones (CS and MA) pass from an average of 3.90 to $4.29 \mathrm{~km} / \mathrm{s}$ in the calcarenite and from 5.10 to $5.64 \mathrm{~km} / \mathrm{s}$ in the marble $\left(\mathrm{Vp}^{*}\right.$ in Table 2). The limits of $\mathrm{Vp}$ fluctuations, between saturated and dry states, are slightly wider in the calcarenite $(7.50 \%$ to $13.07 \%)$ than in the marble $(9.57 \%$ to $12.22 \%)$; rates calculated from data in Table 2.

From the physical point of view, the stones are usually simulated at a two-phase system: solid-vacuum. The solid corresponds to the matrix mineral of the rock and the vacuum corresponds to the interstitial space between minerals in the form of pores (open and closed) and interor intra-granular cracks. At the saturated state, the air occupying the vacuum space of the rock is replaced by water and knowing that $\mathrm{P}$-waves are faster in water (1.45 $\mathrm{km} / \mathrm{s})$ than in air $(0.35 \mathrm{~km} / \mathrm{s})$, so Vp in saturated rocks are obviously higher than those in the dry ones $[27,28]$.

Concerning the effect of fractures on the $\mathrm{Vp}$, the measurements on samples containing an increasing number of "artificial fractures" (1 to 8) parallel between them and perpendicular to the direction of wave propagation show, in both the calcarenite and the marble, a continuous decrease of $\mathrm{Vp}$ according to the increasing number of fractures. This reflects a diminution of the P-waves velocity (energy) caused by the fractures that play a role of physical discontinuities.

By plotting the cumulative diminution rate of $\mathrm{Vp}(\mathrm{Dc})$, according to the number of fractures (Figure 9), we notice that for samples of the dry calcarenite of Salé, the diminution evolves in a gradual but irregular way, which defines a line regression with a low linear coefficient of determination $\left(r^{2}=0.87\right)$ :

$$
\mathrm{Dc}=10.18 \mathrm{NbFr}+10.96
$$

However, for the marble of oued Akrech, the evolution of the $\mathrm{Vp}$ diminution is progressive and more regular, so it defines a linear regression with a coefficient of determination very near to the unit $\left(r^{2}=0.99\right)$ :

$$
\mathrm{Dc}=12.17 \mathrm{NbFr}-10.69
$$

The petrophysical nature would be the main factor that influences the diminution rate of $\mathrm{Vp}$. Indeed, the texture (the grain size, their nature and their arrangement) is an intrinsic parameter determining the degree of roughness of the fractures surface. The surface of the calcarenite, even after rectification, keeps a high roughness due to its great porosity and the presence of quartz grains that can be easily detached from the friable micritic cement. In contrary, the marble surface, particularly after rectification, becomes very smooth because of the homogeneous nature of its carbonate crystals, which are in addition well imbricated.

Thus, for the calcarenite and despite the tightening, the fractures surfaces of the remained space with a number of contact points that vary greatly from one fracture to another (Figure 10(a)). This causes significant losses and variable rates diminution of $\mathrm{Vp}$ according to the morphology of each fracture surface. The relatively smooth surfaces of marble induce a lower and relatively most regular rate of $\mathrm{Vp}$ diminution (Figure 10(b)). The effect of surface roughness of fractures on P-wave velocity was already reported and analyzed in an experimental work of Kahraman [6].

On the other hand, the effect of the planes orientation of fractures on the $\mathrm{Vp}$ depends, in addition to the lithological nature, to other physical processes. The fractures oriented parallel to the direction of P-waves propagation play a role of "waveguide" and might even induce a resonance effect which would involve an activation of

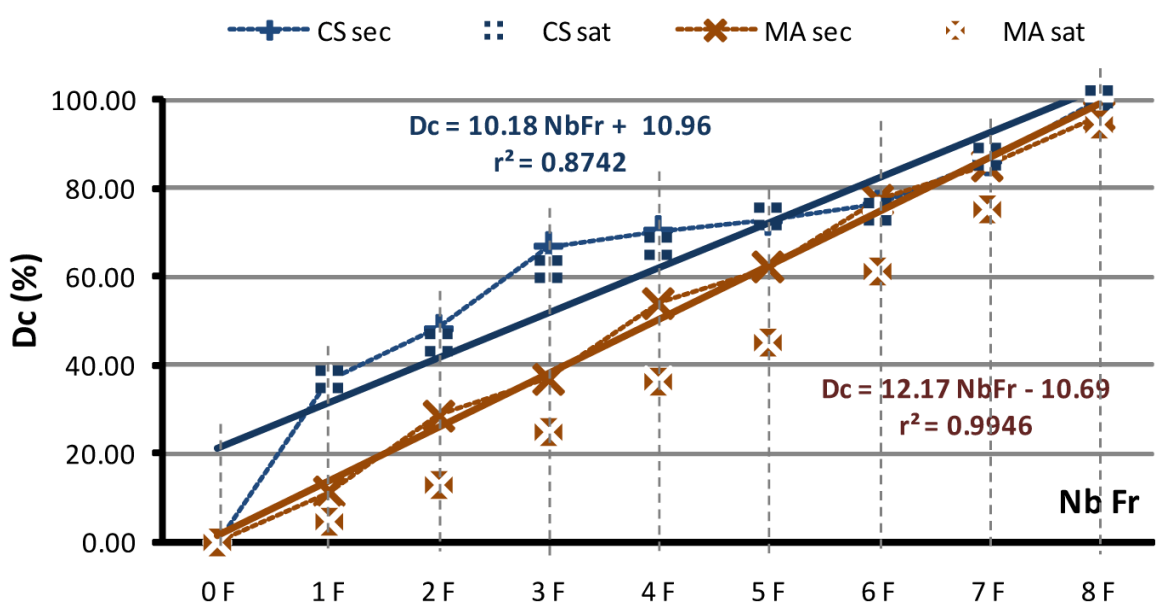

Figure 9. Evolution of cumulative diminution rates (Dc) des Vp according to the number of the fractures in the calcarenite of Salé and the marble of oued Akrech under dry and saturated conditions (the same legend as Figure 6). 

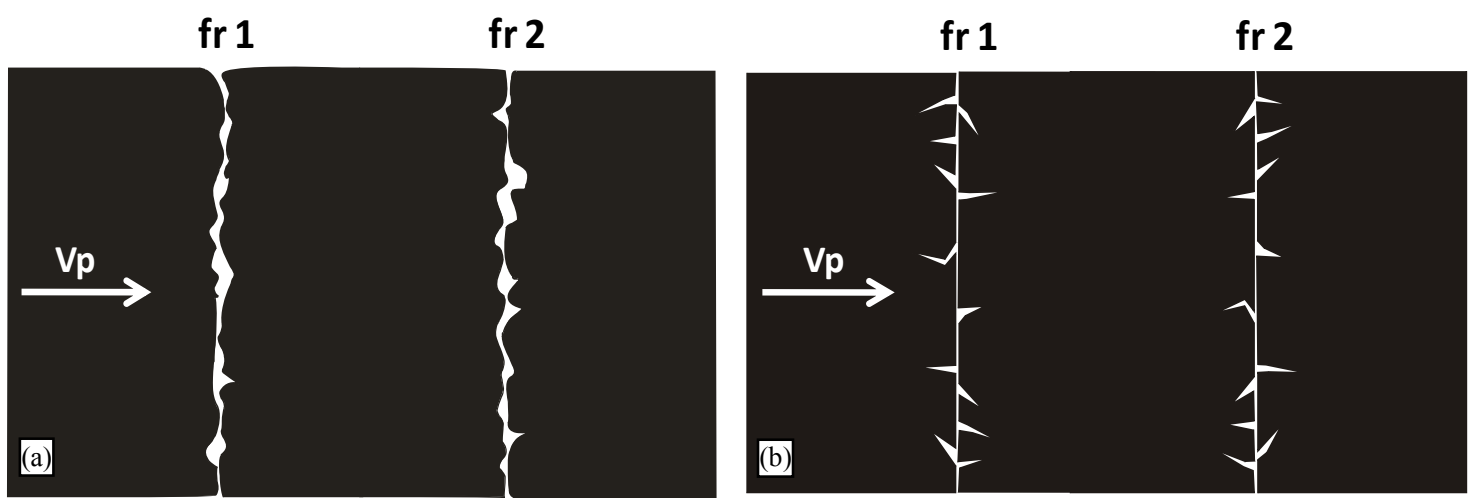

Sample (a): morphology of fr $1 \neq$ fr2 ... Sample (b): morphology of fr $1 \equiv$ fr 2 .

Figure 10. Schematic representation of the fracture's morphology: (a) Calcarenite of Salé; (b) Marble of oued Akrech.

the ultrasonic waves and consequently a slight increase in their propagation velocity wave $[15,23,24,29,30]$.

The diminutions of $\mathrm{Vp}$, much lower through the fractures oriented at $45^{\circ}$ than those caused by the fractures oriented at $25^{\circ}$ and $90^{\circ}$, would be likely related to the compressive nature of the $\mathrm{P}$-waves. Indeed admitting that the P-waves behavior is like a simple constraint, they must obey to physical laws concerning the propagation of the constraints in the solid mediums. In this case, we know that a constraint $(\tau)$ exerted on an inclined surface would depend on the normal stress $(\sigma)$ and the angle of inclination of the surface $(\alpha)$ following the equation:

$$
\tau=\sigma / 2(\sin 2 \alpha)
$$

According to Equation (7), the stress $\tau$ is maximal when $\alpha=\pi / 4\left(45^{\circ}\right)$, which means that the energy transmission of the P-waves would be optimal and therefore its diminution is minimum through the fractures oriented at $45^{\circ}$.

\section{Conclusions}

This study, carried out on two types of Moroccan building stones (calcarenite of Salé and marble of oued Akrech), corroborate the earlier works and confirms the existence of a close relationship between the lithology of rocks and their P-wave velocities (Vp). This is, indeed, the basic principle of the using of $\mathrm{Vp}$ measurement as a method of Non-Destructive Technical (NDT) of the building stones. However, a lot of research still remains to do for reaching of a good-control of the effects of secondary processes (weathering, fracturing $\cdots$ ) on the $\mathrm{Vp}$ variations. This study has particularly emphasized the effect of the fracturing.

In this purpose, measurements of $\mathrm{Vp}$ were made on some samples of Moroccan calcarenite and marble containing "artificial fractures" at a variable number $(\mathrm{F}=1$ to 8$)$ and having different orientation plans $\left(\theta=0^{\circ}, 25^{\circ}\right.$, $45^{\circ}$ and $90^{\circ}$ ).
For the specimen having an increasing number of fractures (fractures perpendicular to the wave propagation direction), the $\mathrm{Vp}$ shows cumulative diminutions $\left(\mathrm{D}_{\mathrm{C}}\right)$ that increase progressively according of the fracture number, but with a regression line that is specific for each type of rocks. Moreover, the unitary diminution rate of $\mathrm{Vp}(\mathrm{Du})$ are much more irregular in the calcarenite stone than in the marble one. This is directly due on the nature of the fracture surface, which is quite rough in the case of calcarenite and smooth in the case of marble. Thus, should we admit that the Vp diminution rate, in fractured rocks, depends both of the number of fractures and the quality of fractures surface (smooth or rough), quality that is directly related to the petrographic nature (texture, grain size, porosity and mineralogy) of the rock.

Moreover, the $\mathrm{Vp}$ diminution rate also varies with the fractures plans orientation. The fractures parallel $\left(\theta=0^{\circ}\right)$ amplify slightly the Vp, playing a role of "waveguide". The resonance phenomenon could also contribute to this amplification. Contrary to what we can think, the fractures oriented at $45^{\circ}$ induced a $\mathrm{Vp}$ diminutions lower than those of fractures oriented at $25^{\circ}$ and $90^{\circ}$. The same trends of diminution, but at variable rates, appear on the samples of the two types of stones at both dry and saturated states. The explanation of this can be found by comparing the propagation of P-waves, which are compression waves, to the transmission of constraints in a solid medium. Thus, the effect of the orientation of fracture planes on $\mathrm{Vp}$ is purely controlled by the laws of solids physic.

The results of this study have a double interest:

1) They furnish a new technological data on the two main building stones of the Rabat area, which will serve for the control and the restoration of the both historical monuments and recent edifices built from these types of stone.

2) They contribute to deepen the knowledge on the behavior of $\mathrm{P}$-wave in the fractured rocks.

This will permit also to extend the use of the ultrasonic 
method as a non-destructive technical for the choice and the control of the quality of building stones.

\section{Acknowledgements}

This study was conducted in the laboratory of Geomaterials and Geoenvironment (Geo M\&E) of the Scientific Institute. Authors acknowledge support from the University Mohammed V-Agdal (UMV-A, Research project: "Plan d'Urgence 2009-2012") and the National Center for Scientific and Technical Research (CNRST, research project: URAC 46). Authors are also grateful to the financial support of the Hassan II Academy for Sciences and Techniques (AH2ST, Research project: V2GV).

We express our thanks and gratitude to the reviewers for their constructive critiques and suggestions.

\section{REFERENCES}

[1] K. Sassa and T. Watanabe, "Velocity and Amplitude of P-waves Transmitted through Fractured Zones Composed of Multiple Thin Low-Velocity Layers," International Journal Rock Mechanics and Mining Sciences \& Geomechanics Abstracts, Vol. 32, No. 4, 1995, pp. 313-324. doi:10.1016/0148-9062(95)00008-5

[2] R. P. Young, T. T. Hill, I. R. Bryan and R. Middleton, "Seismic Spectroscopy in Fracture Characterization," Quarterly Journal of Engineering Geology, Vol. 18, No. 4, 1985, pp. 459-479. doi:10.1144/GSL.QJEG.1985.018.04.16

[3] P. Gaviglio, "Longitudinal Waves Propagation in a Limestone: The Relationship between Velocity and Density," Rock Mechanics. Rock Engineering, Vol. 22, No. 4, 1989, pp. 299-306. doi:10.1007/BF01262285

[4] M. S. King, N. A. Chaudhryand and A. Shakeel, "Experimental Ultrasonic Velocities and Permeability for Sandstones with Aligned Cracks," International Journal Rock Mechanics and Mining Sciences, Vol. 32, No. 2, 1995, pp. 155-163. doi:10.1016/0148-9062(94)00033-Y

[5] T. Chrzan, "The Determination of Rock's Mechanical Properties with the Use of Ultrasounds," Proceedings of the 6th International Symposium on Mine Planning and Equipment Selection, Rotterdam, 1997, pp. 315-318.

[6] S. Kahraman, "The Effects of Fracture Roughness on PWave Velocity," Engineering Geology, Vol. 63, No. 3-4, 2002, pp. 347-350. doi:10.1016/S0013-7952(01)00089-8

[7] L. M. Del Rio, F. Lopez, F. J. Esteban, J. J. Tejado, M. Mota, I. Gonzàlez, J. L. San Emeterio and A. Ramos, "Ultrasonic Characterization of Granites obtained from Industrial Quarries of Extremadura (Spain)," Ultrasonics,Vol. 44, Suppl., 2006, pp. e1057-e1061. doi:10.1016/j.ultras.2006.05.098

[8] A. Kiliç and A. Teymen, "Determination of Mechanical Properties of Rocks Using Simple Methods," Bulletin of Engineering Geology and the Environment, Vol. 67, No. 2, 2008, pp. 237-244. doi:10.1007/s10064-008-0128-3

[9] P. K. Sharmaand and T. N. Singh, "A Correlation between P-Wave Velocity, Impact Strength Index, Slake
Durability Index and Uniaxial Compressive Strength," Bulletin of Engineering Geology and the Environment, Vol. 67, No. 1, 2008, pp. 17-22. doi:10.1007/s10064-007-0109-y

[10] I. El Amrani El Hassani and H. El Azhari, "Evaluation des Propriétés Physico-mécaniques des Pierres de Construction du Maroc à partir des Vitesses des Ondes $\mathrm{P}$ et de la Résistance au Choc," Bulletin de l'Institut Scientifique, Rabat, Vol. 31, 2009, pp. 41-54.

[11] M. Khandelwal and P. G. Ranjith, "Correlating Index Properties of Rocks with P-Wave Measurements," Journal of Applied Geophysics, Vol. 71, No. 1, 2010, pp. 1-5. doi:10.1016/j.jappgeo.2010.01.007

[12] K. Kaneko, I. Inoue, K. Sassa and I. Ito, "Monitoring the Stability of Rock Structures by Means of Acoustic Wave Attenuation," 4th ISRM Congress, Montreux, September 2-8 1979, pp. 287-292.

[13] M. Schoenberg, "Elastic Wave Behavior across Linear Slip Interfaces," Journal of the Acoustical Society of America, Vol. 68, No. 5, 1980, pp. 1516-1521. doi:10.1121/1.385077

[14] M. Fehler, "Interaction of Seismic Waves with a Viscous Liquid Layer," Bulletin of Seismological Society of America, Vol. 72, No. 1, 1982, pp. 55-72.

[15] F. K. Boadu and T. L. Long, "Effects of Fractures on Seismic-Wave Velocity and Attenuation," Bulletin of Seismological Society of America, Vol. 127, No. 1, 1996, pp. 86-110.

[16] S. Kahraman, "A Correlation between P-Wave Velocity, Number of Joints and Schmidt Hammer Rebound Number," International Journal Rock Mechanics and Mining Sciences, Vol. 38, No. 5, 2001, pp. 729-733. doi:10.1016/S1365-1609(01)00034-X

[17] R. Altindag and A. Guney, "Evaluation of the Relationships between P-Wave Velocity (Vp) and Joint Density (J)," 19th International Mining Congress of Turkey, Izmir, 9-12 June 2005, pp. 101-106.

[18] A. Millies-Lacroix, "Carte géotechnique de la Région de Rabat," Notes et Mémoires, Vol. 238, 1974.

[19] L.Asebriy, C. Bucci, I. El AmraniElHassani, R. Franchi, F. Guerrera, M. Martin, C. Patamia, G. Raffaelli, P. Robles-Martin and D. J. Tejera, "Etude Intégrée de la Dégradation des Monuments Historiques Romains et Islamiques de la Ville de Rabat (Maroc): Proposition de Solutions Durables de Prévention et de Restauration," Science and Technology for Cultural Heritage, Vol. 16, No. 1-2, 2007, pp. 45-65.

[20] L. Asebriy, T. E. Cherkaoui, C. Bucci, I. El Amrani El Hassani, R. Franchi, F. Guerrera, M. Martin, C. Patami, G. Raffaelli, P. Robles-Martin, D. J. Tejera and F. Alcala, "Deterioration Processes on Archeological Sites of Chellah and Oudayas (World Cultural Heritage, Rabat, Morocco): Restoration Test and Recommendations," Italian Journal of Geosciences, Vol. 128, No. 1, 2009, pp. 157171.

[21] H. El Azhari and I. El Amrani El Hassani, "Diagnostic and Monitoring of Building Stones Using P-Wave Velocity: Application to Historic Monuments of Rabat (Morocco)," 4th International Congress on Science and Tech- 
nology for the Safeguard of Cultural Heritage in the Mediterranean Basin, Cairo, 6-8 December 2009, pp. 487494.

[22] ASTMA, "Standard Test Method for Laboratory Determination of Pulse Velocities and Ultrasonic Elastic Constants of Rock: D2845-00,” Book of ASTM, 2000.

[23] Y. Guéguen and V. Palciauskas, "Introduction à la Physique des Roches, Herman, Editeurs des Sciences et des Arts," 1992, 299 p.

[24] R. Perrier, "La Sonorité des Roches, Etude de la Résonance Longitudinale," Mines et Carrières, Vol. 78, 1996, pp. 67-73.

[25] R. Perrier, "Les Roches Ornementales," Edition Pro Roc, France, 2004.

[26] L. M. O. Sousa, D. L. M. Suarez, L. Clalleja, D. V. G. Ruiz and R. A. Rodriguez, "Influence of Microfractures and Porosity on the Physico-Mechanical Properties and Weathering of Ornamental Granites," Engineering Geol- ogy, Vol. 77, No. 1-2, 2005, pp.153-168 doi:10.1016/j.enggeo.2004.10.001

[27] A. R. Gregory, "Fluid Saturation Effects on Dynamic Elastic Properties of Sedimentary Rocks," Geophysics, Vol. 41, No. 5, 1976, pp. 721-895. doi:10.1190/1.1440671

[28] S. Kahraman, "The Correlations between the Saturated and Dry P-Wave Velocity of Rocks," Ultrasonics, Vol. 46, No. 4, 2007, pp. 341-348. doi:10.1016/j.ultras.2007.05.003

[29] F. K. Boadu, "Fractured Rock Mass Characterization Parameters and Seismic Properties: Analytical Studies," Journal of Applied Geophysics, Vol. 36, No. 1, 1997, pp. 1-19.

[30] F. K. Boadu, "Predicting the Transport Properties of Fractured Rocks from Seismic Information: Numerical Experiments," Journal of Applied Geophysics, Vol. 44, No. 2-3, 2000, pp.103-113. 